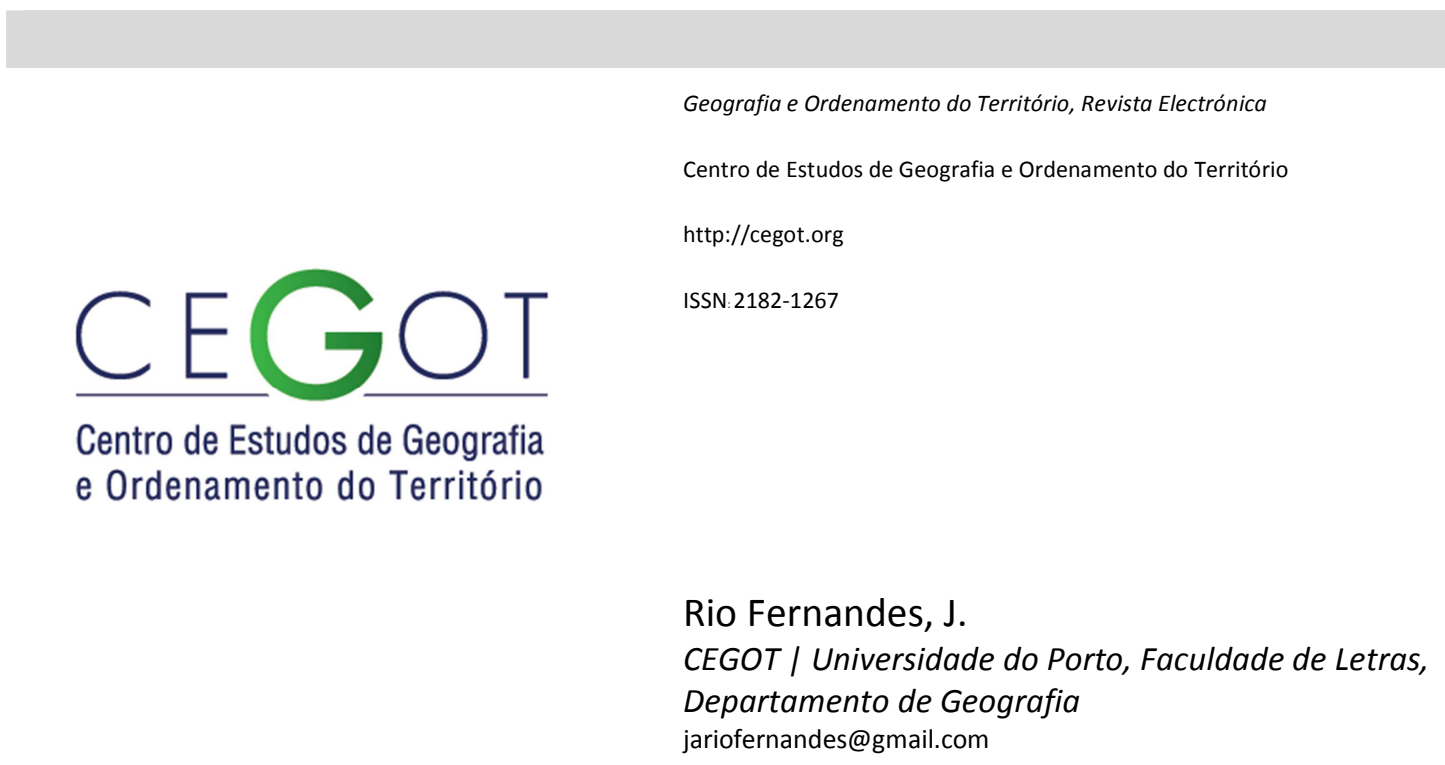

\title{
Apresentação do número e agradecimento a Peter Hall
}

Referência: Rio Fernandes, J. (2014). Apresentação do número e agradecimento a Peter Hall. Revista de Geografia e Ordenamento do Território (GOT), n.o 6 (dezembro). Centro de Estudos de Geografia e Ordenamento do Território, p. 1-6

A disponibilização, universal e gratuita, do sexto número da GOT (Revista de Geografia e Ordenamento do Território) a 30 de Dezembro de 2014, garante a regularidade semestral e constitui prova, espera-se, do continuado reforço da qualidade de uma publicação que celebra hoje o seu $3^{\circ}$ aniversário. Os leitores, na sua diversidade de opiniões, serão disso os melhores juízes, pela leitura que farão do que a revista oferece e pela divulgação que ajudarão a garantir dos resultados do esforço de autores, revisores, editor e adjunto ao editor.

Este número é o primeiro que surge depois da GOT passar a revista indexada, cumprindo todos os critérios do LATINDEX, o que premeia o trabalho feito e incentiva a conseguir responder a exigências maiores. 
Este número 6 é também um número especial por uma outra razão, menos agradável, mas a que com prazer nos associamos, que é a de prestar homenagem a três geógrafos que nos deixaram este ano.

A pensar neles, há dois pequenos textos que abrem esta edição, antecedendo os artigos aceites pela revisão científica. Num primeiro, Lúcio Cunha, coordenador do CEGOT (Centro de Estudos de Geografia e Ordenamento do Território) e membro do grupo de investigação a que os colegas António Pedrosa e Fernando Rebelo pertenceram, deixanos sobre eles um breve apontamento, em jeito de homenagem; num outro, Márcio Moraes Valença, conselheiro científico do CEGOT, faz-nos chegar impressões de uma entrevista que realizou a Sir Peter Hall, semanas antes do seu falecimento.

Se Lúcio Cunha pode bem melhor que eu deixar algumas palavras sobre os nossos colegas do CEGOT e ainda que Márcio Valença se associe a tal no seu texto e pudesse por si só fazê-lo melhor que eu, é meu dever - e motivo de orgulho - homenagear aqui Sir Peter Hall, figura marcante da Geografia da segunda metade do século XX, que nos concedeu o privilégio de fazer chegar um texto que foi publicado no $\mathrm{n}^{\mathrm{o}} 3$ da GOT e que, além disso, abriu na Casa da Música o 1ํㅡㄹ Encontro Internacional do CEGOT que teve lugar no Porto entre 3 e 5 de Março de 2013.

Num tempo em que fazem falta as convicções e se faz apelo ao reforço das relações entre ciência fundamental e aplicada, num tempo em que se reconhece a necessidade dos especialistas conviverem com aqueles cuja sabedoria os faz mais capazes de produzir leituras gerais de síntese, é gratificante recordar Sir Peter Hall.

Geógrafo e urbanista, académico distinto, homem informado e culto, cavaleiro britânico, Hall era um teórico capaz de propostas práticas, assim como de se relacionar com conservadores e socialistas. Talvez por isso tenha sido central na reconversão das docas de Londres - modelo para tantos outros casos de intervenção urbana - apostando aqui não apenas na convergência de vontades, públicas e privadas desde logo, como na valorização do lado oriental da cidade, mais operário e desqualificado, assim como na articulação de escalas, fosse entre cidade e região, como na consideração da inserção mundial e das particularidades locais. Além de muitos artigos e conferências - e tanto mais - encontrou sempre (espantosamente!) o tempo para escrever dezenas de livros, 
onde não apenas deslumbra pela informação acumulada, pela facilidade de ligar o teórico com o empírico, como pela forma refrescante e inovadora como coloca os seus argumentos e ainda pela facilidade e gosto com que se lê o que escreve, talvez porque se perceba uma paixão que se transmite e contagia.

Será por certo injusto que, entre tantas, se destaquem obras suas relativamente a outras, e até mesmo temas entre os que abordou. Por isso, refugio-me numa caso particular, o meu, para, ao mesmo tempo que lamento o que não conheço, realçar, no que pude ler, a importância dada à história das cidades e do urbanismo como contributo central na compreensão das cidades que temos. Esta ligação entre espaço e tempo foi uma constante, numa valorização de pensadores e agentes da transformação do espaço urbano que o levaram a ver a história como essencial enquanto suporte para a ação na construção das cidades que desejamos, face aos seus problemas, os novos e os recorrentes.

Para o compreendermos, é essencial ter lido o tão marcante "Urban and Regional Planning", cuja 1ํㅗ edição remonta a 1975, ou o interessantíssimo "Sociable Cities" que escreveu com Colin Ward, em 1998. Mas, entre todos, destacar-se-á por certo, para mim como para muitos, o mítico "Cities of Tomorrow" (que vai na $5^{a}$ edição), mesmo que hoje pareça mais importante ainda a leitura do monumental "Cities in Civilization", onde a inovação é tratada com uma marcante profundidade e facilidade, de "Polycentric Metropolis" (de 2006, realizado com Kathy Pain), ou ainda de "Urban Futures 2000" (em coautoria com Ulrich Pfeiffer), numa brilhante antevisão aos problemas das cidades de crescimento rápido de boa parte do Hemisfério Sul.

Nestas e noutras obras e em tantas conferências por todo o mundo, assim como na supervisão de projetos e trabalhos académicos, transparece, da reflexão e ação de Peter Hall, uma grande preocupação com a justiça social, a inovação tecnológica e cultural e, de um modo particularmente especial nos últimos anos, com o papel dos transportes, da eficiência energética e sustentabilidade ambiental na construção de uma cidade boa, para vivermos melhor, como fica muito claro no seu último livro "Good Cities, Better Lifes", editado pela Routledge em 2013, ou ainda no texto "Creating transport corridors: refreshing the places other transport hasn't reached" incluído no último "Regional Outlook" editado este ano pelo OCDE sob o título "Regions and cities: where policies and people meet". 
Nestes e noutros temas e obras, sabia identificar e difundir as boas práticas como poucos, insistindo na vantagem nas cidades de pequena e média dimensão e em áreas urbanas das grandes espaços urbanos relativamente densos, estarem bem servidas por transporte coletivo, serem dotados de sistemas energética e ambientalmente eficientes e conseguirem promover a inovação e a inclusão.

Alguns tiveram o prazer de o ouvir em Lisboa, em Aveiro e no Porto. Muitos leram e manterão o prazer de o ler, em tanto do que escreveu, seja no que nunca lemos ou no que precisamos de revisitar, o que inclui algumas das obras mais marcantes da Geografia e do Urbanismo das últimas décadas. Mas, se para muitos fica isso, e para bastantes a felicidade da sua companhia, apenas para mim e para muito poucos fica a memória do prazer de com ele termos percorrido a pé parte da área antiga do Porto. Tencionava voltar. Infelizmente, tal deixou de ser possível a partir de 30 de Julho de 2014.

Mas, perdido Peter Hall, fica o geógrafo e urbanista, nas suas obras e nas intervenções que inspirou, as quais o prolongam, especialmente através dos muitos milhares que, em todo o mundo, têm a consciência do muito que aprenderam e poderão transmitir.

Se, pelas razões expostas, este pode ser visto como um número especial da GOT, ele é todavia muito idêntico aos demais em quase tudo o resto. Desde logo, reúne pouco mais de uma dezena de textos, 13 para se ser exato; depois porque mais uma vez não é todo ele publicado em português, já que há textos em espanhol, francês e inglês; além disso, entre os autores há várias nacionalidades, com destaque para Portugal e Brasil, e, além disso, geógrafos e não geógrafos; por fim, há jovens investigadores e cientistas de nomeada, devendo destacar-se entre estes Augusto Perez Alberti, catedrático da Universidade de Santiago de Compostela e consultor científico do CEGOT, que assina um texto sobre metodologia e classificação de tipos de paisagem com Manuel Borobio Sanchiz, Francisco Rodríguez e Melania Pérez.

Como é habitual, os textos estão ordenados pela ordem alfabética do apelido do primeiro autor. Sobre eles, não terei capacidade para, em poucas palavras, acrescentar algo de relevante ao que pode resultar da sua leitura, muito menos posso substituir-me aos autores na síntese que fizeram chegar. Opto por isso por convidar todos à sua 
leitura - e porque não há submissão de um texto? - e por dar conta da diversidade dos temas, escalas e espaços territoriais.

Relativamente aos anteriores números, é de notar a existência de dois textos onde se abordam preocupações associadas ao ensino da Geografia, com o pensamento geográfico e as tecnologias de informação a serem o objeto dos contributos que nos chegam de geógrafos das universidades de Minho e Porto (Rui Freitas e Marisa Freire), e de Coimbra e Lisboa a que soma docente de ensino secundário (Olga Maciel, Adélia Nunes e Sérgio Claudino), respetivamente.

Destaca-se também o facto de 5 dos 13 artigos nos chegarem desde o Brasil, numa demonstração da sua importância acrescida, desde logo na produção científica em Geografia e Ordenamento do Território em língua portuguesa. Os autores brasileiros, geógrafos praticamente todos, tratam temas muito diversos, ligados à climatologia, no caso de Hiago Barbosa e Flaviane Santos; à formação na nação, vista por Cleyde Esteves desde uma perspetiva da geografia histórica e cultural; à chamada economia solidária, tema de Sílvia Ortigoza; à avaliação dos municípios vista a partir da sua dimensão por Ralfo Matos e Rodrigo Ferreira, e ao património urbano, no caso de Francine Ribeiro e Sidney Vieira.

Tanto no caso de autores brasileiros como de portugueses, outro destaque é o da pluralidade de instituições de sede. No primeiro caso estão representadas as universidades Estadual de São Paulo (Pelotas e Rio Claro), Federal do Rio de Janeiro, Federal de Minas Gerais e Estadual de Pelotas; no segundo, boa parte das universidades públicas: Coimbra, Évora, Lisboa, Minho e Porto.

Assinala-se com especial gosto a entrada de um geógrafo francês de renome, René-Paul Desse, titular da Universidade de Rennes, que aborda o tema muito atual da resiliência, na sua adaptação a questões urbanas, em especial às que se associam ao comércio das cidades francesas.

Hélder Diogo trata também uma realidade francófona, trazendo-nos uma reflexão a propósito da sócio-demografia dos emigrantes portugueses no Luxemburgo.

Há ainda um texto de geografia rural, que nos chega desde as Ciências Agrárias da Universidade de Évora, o qual trata a agricultura em espaço urbano. 
Eduardo Medeiros é o autor de uma interessante reflexão a propósito de uma muito falada europeização das políticas territoriais, tratando especialmente o caso das políticas orientadas para a coesão e a sua adaptação a Portugal no período 1989-2013.

Por fim, temos de agradecer a Ana Melo, Fernando Lagos Costa, Ana Cabral e Maria Nunes a abordagem da fronteira de Guiné-Bissau, lembrando-nos um de muitos espaços mundiais de "periferia esquecida", num interessante ensaio metodológico às condições de acessibilidade e uso do solo em área de fronteira. 